\title{
Relationships between risk of causing a motorway crash in Austria and attributes of drivers
}

\author{
Wolfgang J. Berger ${ }^{*}$ (D) and Reinhard Hössinger
}

\begin{abstract}
Objective: The emphasis of the study presented in this paper was to identify the attributes of drivers who are prone to cause a motorway crash. It was induced byambitions to enhance the effectiveness of traffic safety campaigns by identifying subgroups of drivers more precisely.

Method: For this purpose we conducted an accident data analysis of all injury crashes 2012-2014 on Austrian motorways. Since 2012 it is possible for the police to label the "mainly responsible person" for the crash in the Austrian electronic accident recording system. It turned out that the quality of the data had some limitations, which required considerable pre-processing. The analysis by comparing the proportions of "mainly responsible" and "not responsible" drivers was done using descriptive statistics and logistic regression models. The binary characteristic, if a person was, according to the police, mainly responsible for the crash served as response variable. It was regressed on various personal and vehicle characteristics in order to identify their influence on the probability of causing a crash.
\end{abstract}

Results/Conclusions: The results yield apparent tendencies, some of which support well-known pattern, e.g., the disproportionally high risk of motorcyclists and - to a lesser extent - young and elderly car drivers to cause an accident. Other results were less expected, e.g., the higher risk of foreign car drivers (compared to Austrian drivers) as well as drivers of light trucks, whereas drivers of heavy trucks revealed a below-average risk of causing a crash. The differences between male and female car drivers were small from young to middle age and fully disappeared in the high age group. There is some evidence that the frequency and experience of driving on a motorway have more influence on the risk of causing a crash than the driver's gender. From this we conclude that motorway safety campaigns should on the one hand focus on the abovementioned groups of high risk drivers and on the other hand, in terms of car drivers, equally address both male and female drivers.

Keywords: Safety, Motorway, Accident risk, Accident data, Accident analysis, Safety campaign

\section{Background}

The overall length of the Austrian motorways (termed either A-roads or S-roads) is a little more than $2200 \mathrm{~km}$. They permit automobile use only (minimum speed $=60$ $\mathrm{km} / \mathrm{h}$, general speed limit $=130 \mathrm{~km} / \mathrm{h}$ ), have no at-grade junctions, and are toll roads (time-based vignette system for vehicles up to 3.5 t; distance-based charge system for vehicles over $3.5 \mathrm{t}$ ). Most of these roads have separated carriageways with 2 or 3 (sometimes 4) lanes, median

\footnotetext{
* Correspondence: w.j.berger@boku.ac.at

Institute for Transport Studies, Department of Landscape, Spatial and Infrastructure Sciences, BOKU - University of Natural Resources and Life Sciences, Peter-Jordan-St. 82, A-1190 Vienna, Austria
}

barriers of concrete or steel, gradients lower than $4 \%$ (about 5.5\% at the maximum), and are equipped with 2.5 to $3 \mathrm{~m}$ wide hard shoulders.

In terms of accident occurrence on the Austrian motorways, during the last decade the number of fatalities decreased by a third, from 81 in 2008 to 56 in 2017. However, the number of injury crashes as well as the number of persons injured from crashes even increased a bit (2008: 2091 crashes with 3344 persons injured; 2017: 2352 crashes with 3474 persons injured [33];). Each of these crashes and also those with damage to property only (which are not systematically recorded) constitutes an event which may disrupt the traffic flow or even lead to extensive congestions. This 
reduces the reliability of the highway, which in turn damages the reputation of the road operator. These consequences make a sufficient case for the Austrian motorway operator Asfinag to promote safer driving on its roads by running safety campaigns time and again.

Until 2011, the accident documentation of injury crashes by police was done non-uniform with different software tools or even by typewriter; the files remained at the police station, e.g. for subsequent court cases. For each injury crash, a standardised paper form was filled in by the police officers additionally to the accident documentation and transmitted to the Austrian Office for Statistics. In January 2012, the system has been changed. Since then the accident documentation is done electronically by a computer program specifically developed for this purpose. The accident record is an extract file of this documentation. With this conversion it is now possible for the police to provide a lot more information about the accident than before when using the paper form. One of the entirely new features is the labelling of the person who is, by police, considered the "mainly responsible person" for the crash. There is, however, no standardised rule how to identify the mainly responsible driver. It is up to the police officer whether she or he ticks the respective box for none, one, or several persons involved in the crash. To investigate the attributes of these "mainly responsible drivers" according to the police is the focus of this paper.

\section{Determinants of crash risk on motorways}

According to Elvik [11] "The number of risk factors that influences accidents is vast. Nobody can enumerate all these risk factors, yet their effects on accidents may display striking regularities." The well-known determinants of accident risk include some situational factors, which cannot be addressed in this study, because situational characteristics are not recorded in the Austrian accident documentation. These include increasing speed (see e.g. [11]), large speed differences (see e.g. [1]), decreasing driver headways (see e.g. [4]), bad weather conditions (rainfall for instance was found to be positively correlated with the number of injury accidents on motorways in both France and the Netherlands [2]), and the current traffic volume. Regarding the latter, Martin [26] observed that crash rates on French motorways are by far highest at very low traffic volumes; they reached a minimum at around 1000-1500 vehicles/h and then increased again with increasing volumes. The high rates at low volumes are mainly produced by single vehicle crashes, whereas in most crashes at high volumes two or more vehicles were involved.

This study focuses on those determinants of accident risk, which relate to the persons and vehicles involved in the crash, because they are available in the Austrian accident documentation. These factors include age, gender, type of vehicle, and familiarity with the "appearance" of motorways in Austria.

Indisputably, driving a vehicle safely (i.e. get the ability to detect and control traffic hazards in time) improves continuously as a result of exposure, resulting in a drop of accident rates as annual driving distances increase [13]. Additionally, high mileage drivers may drive to a higher proportion on motorways which, in consequence, leads to more experience with driving on a motorway. Furthermore, age and driving experience are usually confounded, because most people do their driving license at an early age.

Age is also associated with other factors beyond the mere experience, which can increase the accident risk, inducing the well-known U-shaped relationship between age and crash rates (driver crash involvement per mileage of exposure). These rates are roughly three times higher for young drivers (up to about 25 years) than for medium aged adult drivers, and then grow again for elderly drivers of about 65 years or more [12, 27, 30]. The higher risk of younger drivers results from the combination of riskier driving [32], limited driving experience, the tendency to overestimate driving skills [15] driving lower quality vehicles $[17,41]$ and other age-related situational risks [9]. Elderly drivers may be at greater crash risk due to increasing age-related diseases as well as mental, psychological and neurological restrictions, e.g. declining cognitive skills, increasing reaction time or growing impairments of judgement under time pressure $[10,20,21,37]$.

When it comes to the gender-specific risk of causing a crash, Constantinou, Panayiotou, Konstantinou, Loutsiou-Ladd, and Kapardis [6] emphasize the strong relationship: "males are indeed the high risk group for road traffic accidents". This is in line with the results of a cluster analysis of different personality and drivingrelated measures of young drivers conducted by Lucidi et al. [24]. For three quarters it were males who composed the "risky drivers" cluster, whose members, compared to those of the other two clusters, perceived their risk to be involved in a crash as lower, but actually had more crashes. This result is questioned by a metaanalysis of Elvik et al. [12], who conclude that, though in young drivers up to the age of about 30 men tend to have a higher crash rate than women, all ages taken together the mean crash rate is higher for women than for men. This surprising finding seems to result from the confounding effect of driving experience, because later on (p. 86-87) they present a study of Forsyth, Maycock, and Sexton [16], which shows that the lower accident rate of men follows from the higher average annual driving distance; for a given driving distance men have always a higher accident rate. Lourens, Vissers, and Jessurun [23] also highlight that there is a significant relationship 
between annual mileage and crash involvement. If corrected for annual mileage, the effect of the driver's age is still remaining, but the effect of gender disappears.

The type of vehicle plays a role in itself and is also confounded with gender. It is well known that the vast majority of heavy truck drivers are men. Most of them are professionals who have to perform regular medical checks and may have above-average experience in driving on motorways. In Austria, truck drivers have to observe strict legal regulations of driving periods $(9 \mathrm{~h}$ per day in maximum), break periods ( 45 min break after $4.5 \mathrm{~h}$ of driving), and rest periods (normally $11 \mathrm{~h}$ per $24 \mathrm{~h}$ and $9 \mathrm{~h}$ uninterrupted per day). This reduces the risk of fatigue-related crashes, which are less a problem for truckers than for car drivers. This result complies with findings of Summala and Mikkola [31] some 20 years ago. The general speed limits for heavy trucks on Austrian motorways $(80 \mathrm{~km} / \mathrm{h}$ during daytime and $60 \mathrm{~km} / \mathrm{h}$ in the night-time from 22:00 p.m. to 05.00 a.m.) are much lower than for other vehicles, which further reduces the risk of speed-related crashes.

Motorcyclists are also predominantly men, which is, according to Lin and Kraus [22], one of the nonmodifiable factors of higher risk for motorcycle crashes. The relative injury rate (risk of injury per mileage of exposure on all roads) compared to car drivers seems to be somewhere around 5:1 [28] up to $12: 1$ ([12], p. 56). However, this high risk of injury is largely due to the vulnerability of motorcyclists on the condition that they are involved in an accident; it says little about the unconditional risk of causing an accident. Horswil and Helman [19] suggest that, relative to car drivers, the influence of motorcyclists' behaviour on their accident risk may be surprisingly small.

In contrast to drivers of heavy trucks, for motorcyclists it may be assumed that the share of motorway mileage is disproportionally low. From own experience as a motorcyclist it can be noted that many motorcyclists avoid the boring and inconvenient riding on a motorway whenever possible but prefer travelling along rural roads.

The alignment of motorways (e.g., comparatively high curvature of mountainous motorways in Austria) and the road equipment (e.g., design and colour of direction signs, design and meaning of road markings, for example whether they provide slow lanes for trucks only) differ between many European countries. This may represent a challenge for foreign drivers as well as first-generation immigrants (16.5\% of the Austrian population, see [35]). These drivers might be not fully familiar with the Austrian standards and the "appearance" of Austrian motorways.

From these considerations can be derived some hypotheses about the risk of causing a motorway crash: It is relatively low for (a) female drivers and (b) drivers of heavy trucks, whereas it is relatively high for (i) young and elderly drivers, (ii) particularly young males, (iii) motorcyclists, and (iv) foreign drivers.

In terms of road safety campaigning, the efficacy of isolated information campaigns is often poor, if measurable at all ([12], pp. 867-873). On the other hand, following the social marketing approach with its objective "to influence and change social behaviours in the interest of the target audience" ([8], p. 87) the effectiveness of a campaign might be enhanced by defining specific target groups rather than addressing the whole population (ibid., p. 107). This is supported by the results of a metaanalysis of road safety campaigns [29], which indicates that "immediacy" in the delivery of a massage is beneficial to campaign effects on accidents, e.g. achievable by either or both identifying a target group and roadside delivery of the message. To possibly increase the accuracy of planned campaigns the Asfinag commissioned a project [3] with the aim to identify crash prone groups of drivers on motorways by their socio-demographic characteristics. The underlying idea was to compare the drivers who caused the accident according to police (see Section 1) with those who were merely involved but did not cause the accident. These comparisons are performed simultaneously for multiple characteristics using logistic regression models.

\section{Data basis}

A dataset with all injury crashes 2012-2014 on Asfinag roads $(n=6868)$ was provided by Asfinag. It includes 132 columns, which in turn contain hundreds of codes denoting the location/time, the type and the scene of the crash, the sequence of events, and attributes of the $\operatorname{road}(\mathrm{s})$ and vehicle(s)/person(s) involved. Each line represents one involved person $(n=18,140)$. According to the objectives of the analysis only "typical" motorway crashes were of interest, i.e. crashes which happened on the main carriageway or on a slip road. More than 700 "atypical" motorway crashes were omitted, e.g. crashes on at-grade intersections of slip roads with non-Asfinag roads (see Table 1); they were selected by using information about road numbers, road categories, and crash types of the Austrian accident typology [14].

In a second step the drivers who were mainly responsible for the crash were identified. The labelling of the mainly responsible person by police could not be fully trusted. Maybe due to "excessive demand" of the police officers while handling the new system (e.g. the high number of choices required) the answers were sometimes not plausible. For instance, in quite a number of cases all drivers involved in a multi-vehicle crash were assigned as "mainly responsible", and in some cases this even applied to a number of vehicle passengers. On the other hand, a lot of crashes did not report any mainly 
Table 1 Injury motorway crashes 2012-2014 on Asfinag roads

\begin{tabular}{|c|c|c|c|c|c|}
\hline & Crashes & Drivers involved & mainly responsible & not responsible & $\begin{array}{l}\text { responsibility } \\
\text { not specified }\end{array}$ \\
\hline All injury crashes & 6868 & 13,188 & & & \\
\hline \multicolumn{6}{|l|}{ "Atypical" motorway crashes } \\
\hline $\begin{array}{l}\text { Crashes at at-grade intersections of slip roads with } \\
\text { non-Asfinag roads, right-angled collisions }\end{array}$ & 443 & & & & \\
\hline Frontal collisions & 100 & & & & \\
\hline Collisions between turning vehicles, with parking vehicles & 40 & & & & \\
\hline Collisions of undefined type between two or more vehicles & 135 & & & & \\
\hline Remaining basic population of crashes and drivers & 6150 & $11,658100 \%$ & $502943.1 \%$ & $391333.6 \%$ & $271623.3 \%$ \\
\hline
\end{tabular}

responsible driver, although it had been a single vehicle crash. Based on personal conversations with police officers there might be various reasons for this flaw. The electronic accident recording system is quite challenging and some officers might not have the necessary skills or did with the best intentions some wrong clicks, in particular those who do not use the system regularly. Moreover, some police officers have apparently only filled in the required fields but not the optional fields.

This required considerable pre-processing in order to obtain fairly useful data, because there is no software available yet to conveniently prepare and evaluate the optional items in the accident dataset. Particular attention was paid to the response variable of the analysis. A driver is determined as "mainly responsible for the crash", if.

- exactly one driver per crash is labelled as "mainly responsible" and/or.

- it was a single vehicle crash (irrespective of whether or not the driver had been labelled as mainly responsible).

The complementary group of "not responsible drivers" consists of all drivers involved in a crash with two or more vehicles, who are not the one and only "mainly responsible" driver. The data preparation resulted in a dataset with 6150 crashes and 11,658 drivers involved,
5029 of which $(43 \%)$ were flagged as "mainly responsible" and 3913 (34\%) as "not responsible" (see Table 1).

As can be seen in Table 2, the percentage shares of vehicle types are similar in both groups of mainly responsible drivers and all drivers involved in motorway crashes: over 4 out of 5 are passenger car drivers, almost 1 out of 6 truck drivers, and over 1 out of 50 motorcyclists. Concerning the gender, around three quarters are men and one quarter women. But Table 2 also reveals some differences. The shares of mainly responsible motorcyclists and light truck drivers are higher than the corresponding shares of all involved drivers; the opposite applies to drivers of heavy trucks. Furthermore, the gender split of motorcyclists differs between mainly responsible and all involved drivers, indicating a higher accident risk for male motorcyclists. The gender split of car drivers is, however, very similar in both groups of mainly responsible and all involved drivers.

These descriptive results indicate that it is worth taking a closer look at the related data by means of a model-based analysis of the influencing factors on the risk of causing a crash. For the following analysis, the records of those 2716 drivers without specified responsibility (see Table 1) were discarded.

\section{Analysis method}

The binary variable, whether or not a person was mainly responsible for the crash, constitutes the main outcome

Table 2 Vehicle drivers involved and drivers "mainly responsible" for the crash

\begin{tabular}{|c|c|c|c|c|c|c|}
\hline \multirow[t]{2}{*}{ Type of vehicle } & \multicolumn{3}{|c|}{ All drivers involved } & \multicolumn{3}{|l|}{ Drivers "mainly responsible" } \\
\hline & Number & Percentage & $\begin{array}{l}\text { Percentage } \\
\text { Male: Female }\end{array}$ & $\begin{array}{l}\text { Number } \\
\text { (\% of all drivers involved) }\end{array}$ & Percentage & $\begin{array}{l}\text { Percentage } \\
\text { Male: Female }\end{array}$ \\
\hline car & 9551 & 81.9 & 68: 32 & $4107(43.0)$ & 81.7 & 69: 31 \\
\hline truck $\leq 3.5 \mathrm{t}$ & 829 & 7.1 & 97: 03 & $388(46.8)$ & 7.7 & 95: 05 \\
\hline truck $>3.5 \mathrm{t}$ & 985 & 8.4 & 100: 00 & $379(38.5)$ & 7.5 & 99: 01 \\
\hline motorcycle & 241 & 2.1 & 85: 15 & $138(57.3)$ & 2.7 & 91: 09 \\
\hline bus & 40 & 0.3 & 97: 03 & $14(35.0)$ & 0.3 & 93: 07 \\
\hline others & 12 & 0.1 & 89: 11 & $3(25.0)$ & 0.1 & 100: 00 \\
\hline total & 11,658 & 100.0 & 73: 27 & $5029(43.1)$ & 100.0 & $74: 26$ \\
\hline
\end{tabular}


variable of the analysis. Following the characteristic of this variable, we applied binomial logit models to estimate the probability of being mainly responsible for a crash conditional on various predictors (Tables 3 and 4). In one case (Table 5) we applied a trinomial model with the type of accident as outcome variable. The logit models allow for a simultaneous test of several predictors, which seems necessary given the confounding effects mentioned in Section 2. The predictors used in the models include attributes of drivers and vehicles involved in the crash, in particular gender, age nationality of driver, types of vehicle, and nationality of license plate. The models were estimated in R 3.5.1. The R-code builds on the maxLik package [18]. The estimated parameters indicate the degree to which a particular variable contributes to the probability of a particular response, e.g. being responsible for an accident or causing a particular type of accident given the person has caused an accident. Robust standard errors were calculated using the Eicker-Huber-White sandwich estimator [44].

\section{Results}

The data reveal some considerable correlations among the potential explanatory variables. Most importantly, all other vehicle types than private cars are predominantly driven by men (see Table 2). Furthermore, heavy trucks reveal a higher share of foreign drivers (64\%) than all other vehicle types (e.g. cars: 28\%). These correlations may cause confounding effects and biased parameters if estimated simultaneously. Therefore, we tested a joint model against two separate models for vehicle types and personal characteristics. Most parameters were similar, but the effect sizes of "foreign drivers" and the vehicle type "heavy truck" were diminished in the joint model. The reason is most likely a confounding effect between these two variables, because they are positively correlated but have opposite signs. We thus decided to go with the separate models: one with all drivers and the vehicle types as main predictors (Table 3) and another one with car drivers only and personal characteristics as predictors (Table 4). The separate model for car drivers is also justified by the fact that this group constitutes the main target group of most traffic safety campaigns of the Austrian motorway operator.

The model in Table 3 yields the influence of different vehicle types on the risk of causing a motorway crash. The gender variable was included to control for the confounded effects of vehicle type and gender, because all other vehicle types than private cars are predominantly driven by men, which is obvious from the high percentage of male drivers involved in accidents (see Table 2). According to this model, the type of vehicle plays an important role for the risk of causing an accident. Motorcyclists reveal a particularly high risk; the deviation from car drivers (reference group) is highly significant. Drivers of light trucks are also more at risk of causing a crash than car drivers, although the difference is only borderlinesignificant. On the other hand, drivers of heavy trucks have a significantly lower risk than car drivers.

Most results in Table 3 are in line with the hypotheses stated in Section 2. Female drivers exhibit a somewhat lower risk of causing a motorway crash than male drivers (as expected). The same applies to drivers of heavy trucks in comparison to car drivers (as expected). The motorcyclists' risk of causing an accident is significantly higher than for car drivers (as expected). However, please note from Table 2 that the share of mainly responsible motorcyclists is with $57 \%$ not far away from the share of mainly responsible car drivers (43\%). The difference is by far lower than the ratio of general injury rates which, as mentioned in Section 2, ranges up to estimated 12:1. This is obvious since the high injury rates are caused by the high vulnerability of motorcyclists.

Table 3 Binomial logit model of "not responsible drivers" (alternative 1 = reference) and "mainly responsible drivers" (alternative 2); sample = all drivers with specified responsibility involved in a motorway crash; predictors = vehicle type and gender (reference vehicle type $=$ car; reference gender $=$ male)

\begin{tabular}{|c|c|c|c|c|}
\hline Variable & Parameter estimate & $\begin{array}{l}\text { Robust } \\
\text { std. error }\end{array}$ & $\begin{array}{l}\text { Robust } \\
\mathrm{t} \text {-value }\end{array}$ & $\overline{p \text {-value }}$ \\
\hline constant of alternative 1 & 0.000 & & & \\
\hline constant of alternative 2 & 0.275 & 0.029 & 9.646 & 0.000 \\
\hline gender $=$ female & -0.112 & 0.050 & -2.254 & 0.024 \\
\hline vehicle type $=$ motorcycle & 0.557 & 0.154 & 3.624 & 0.000 \\
\hline vehicle type = light truck & 0.153 & 0.085 & 1.813 & 0.070 \\
\hline vehicle type $=$ heavy truck & -0.174 & 0.079 & -2.203 & 0.028 \\
\hline
\end{tabular}


Table 4 Binomial logit model of "not responsible drivers" (alternative $1=$ reference) and "mainly responsible drivers" (alternative 2); sample $=$ car drivers with specified responsibility involved in a motorway crash; predictors = personal and vehicle characteristics (reference gender $=$ male; reference nationality $=$ Austria)

\begin{tabular}{|c|c|c|c|c|}
\hline Variable & Parameter estimate & $\begin{array}{l}\text { Robust } \\
\text { std. error }\end{array}$ & $\begin{array}{l}\text { Robust } \\
\text { t-value }\end{array}$ & $p$-value \\
\hline constant of alternative 1 & 0.000 & & & \\
\hline constant of alternative 2 & 2.804 & 0.170 & 16.480 & 0.000 \\
\hline age in years & -0.125 & 0.008 & -15.177 & 0.000 \\
\hline age in years - squared & 0.001 & 0.000 & 14.180 & 0.000 \\
\hline gender $=$ female & -0.108 & 0.052 & -2.07712 & 0.038 \\
\hline nationality of driver $=$ foreign & 0.286 & 0.054 & 5.252 & 0.000 \\
\hline
\end{tabular}

Number of observations: 7342

null log-likelihood: -5089.087

constant log-likelihood: -5037.181

final log-likelihood: -4898.092

McFadden's rho squared: 0.038

Moreover, many types of crashes that motorcyclists "typically" are involved in, e.g., crashes related to low conspicuity [39] like in urban zones or at at-grade junctions, or cause, e.g., on winding rural roads, can hardly occur on a motorway. In line with Horswil and Helman [19] who did not assume motorcycle drivers compared to car drivers being at much higher risk to cause a crash the proportion of roughly 1.3:1 seems certainly within the possible range.

The higher risk for drivers of light trucks was not expected but is seems quite plausible. Unlike for heavy vehicles the pricing for light trucks is time-based and not mileage-based. Moreover, drivers of light trucks do not face special limitations, but have the same speed limits (generally $130 \mathrm{~km} / \mathrm{h}$ ) and unrestricted driving time as passenger cars. Hence it became increasingly attractive for carriers to use light trucks, reflected by the disproportionate increase of $11.5 \%$ of the total number of light trucks in Austria from 2011 to 2016 (in the same period the share of heavy trucks dropped by $3.3 \%$ and the share of cars increased only by $6.6 \%$; see Statistik Austria [34]. According to Broughton, Baughan, Pearce, Smith, and Buckle [5], drivers of light trucks are often driving under time pressure. Irrespective of whether the vehicles are used for freight transport or other purposes, e.g., by craftsmen for transporting tools and materials or a group of colleagues, and although the vehicles might be heavily laden they are yet driven with the same high speed as cars. Altogether, this might explain that the share of "mainly responsible" drivers of light trucks turns out to be disproportionally high.

The model in Table 4 addresses the question if and to what degree the risk of causing a motorway accident can be attributed to personal characteristics. In order to

Table 5 Multinomial logit model of three different crash types (reference type = run-off crash); sample= mainly responsible car drivers involved in a motorway crash; predictors = age and gender (reference gender = male)

\begin{tabular}{llll}
\hline Variable & Parameter estimate & $\begin{array}{l}\text { Robust } \\
\text { std. error }\end{array}$ & $\begin{array}{l}\text { Robust } \\
\text { t-value }\end{array}$ \\
\hline const. of alt. 1 = run-off crash & 0.000 & & -5.089 \\
const. of alt. 2 = rear-end crash & -1.085 & 0.213 & -8.795 \\
const. of alt. 3 = lane change crash & -3.195 & 0.363 & 5.082 \\
age on alt. 2 & 0.053 & 0.010 & -4.797 \\
age-squared on alt. 2 & -0.001 & 0.000 & -6.517 \\
gender = female on alt. 2 & -0.492 & 0.075 & 3.839 \\
age on alt. 3 & 0.065 & 0.017 & -3.301 \\
age-squared on alt. 3 & -0.001 & 0.000 & 0.000 \\
gender = female on alt. 3 & -0.101 & 0.125 & -0.811 \\
\hline
\end{tabular}

Number of observations: 3841

null log-likelihood: -4219.770

constant log-likelihood: -3547.572

final log-likelihood: - 3505.007

McFadden's rho squared: 0.169 
control for the abovementioned confounding effects, this model includes only car drivers, which make by far the largest group of drivers (and therefore also the largest group of drivers involved in accidents). Among the three predictors included in Table 4 age is by far the strongest. Please note that the two variables "age" and "age squared" represent a 2 nd order polynomial function with linked parameters, which must be interpreted in relation two each other. The combination of a negative linear effect and the smaller positive effect of the squared term indicates that the effect of the age on the accident risk has a U-shaped curve (as expected). In this particular case, the difference between young and middle-aged drivers is larger than the difference between middle-aged and old drivers. The gender variable reveals a lower risk of women (as expected), although this effect is relatively small and only borderline-significant (see Fig. 1).

The U-shaped relationship with respect to age supports a well-known fact as mentioned in Section 2. However, the differences in the shares of "mainly responsible" across different age groups are distinctly smaller than those reported by e.g. [12] (see Section 2). A reason for the smaller differences might be that our sample consists of crashes on motorways only, whereas crash rates cover the crashes on all types of roads. Driving on urban roads and rural highways is much more demanding than driving on a motorway, with higher demand on the driver's observation, anticipation, judgment of situation, and quick reaction. Please also note in Fig. 1 that the difference between the share of mainly responsible males and females is quite constant around 3$4 \%$ up to the age group $45-54$, but reduces in higher age and finally disappears entirely. This pattern indicates that young and adult male drivers are indeed slightly more accident prone than female drivers, but the typical risk-increasing factors of young drivers also apply to women (riskier driving, limited driving experience etc., see Section 2). Furthermore, the age-related adverse effects on the driving skills seem to apply equally to both genders.

Another strong predictor with high significance and considerable effect size is the nationality of the driver, indicating a higher risk of foreign drivers. This underlines the importance of being familiar with the specific "appearance" of Austrian motorways (see Section 2) but has most likely other reasons as well. Austrian motorways are heavily used by holiday travellers in winter and summer season, often starting far away from northern countries (Germany, Czech Republic, Netherlands, Poland etc.) heading either towards touristic destinations in Austria or south towards the Adriatic region and later on back home. Increasing time of monotonous driving on a motorway - maybe including long time in heavy congestion - is well-known for leading to a sort of "driving lethargy", with cumulative mental as well as physical fatigue and drowsiness. It causes performance deficits related to executive control [25] - as is frequently required for driving -, limits the ability to process relevant information and thus may result in tunneling of attention [42] and inattentional blindness ("looked but did not see"; see [40]). All of this can increase the crash risk of long-distance travellers on a motorway [7].

The model in Table 5 addresses the question if and to what degree personal characteristics make a difference on the type of accident, given the person was mainly responsible for an accident according to the police. For this purpose we included only "mainly responsible car drivers" in the model, thereby asking the question if the driver's age and gender have an effect on the allocation to a specific type of crash. We included three types of

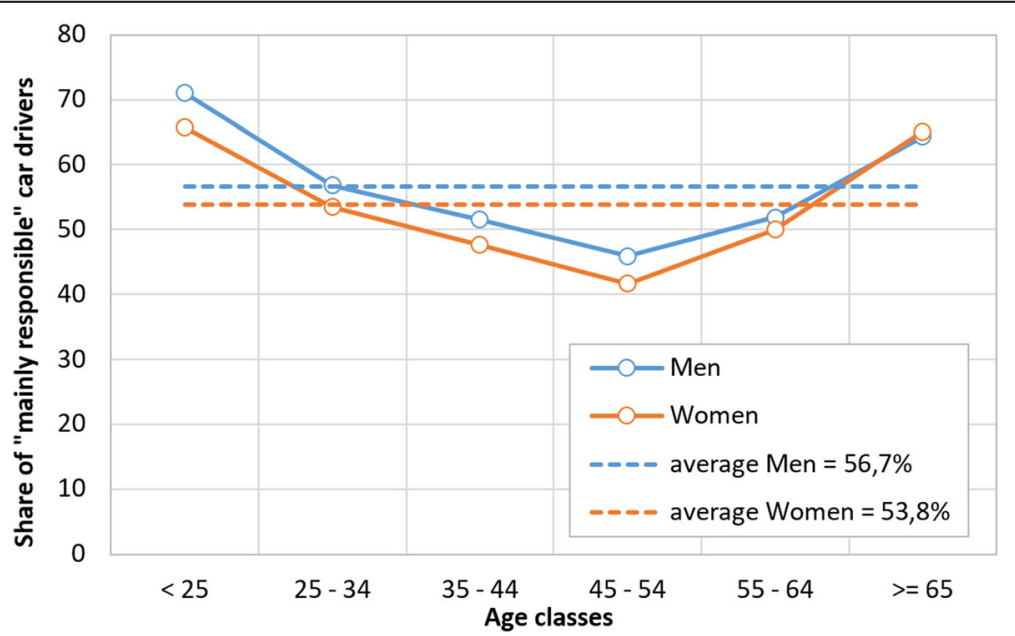

Fig. 1 Share of mainly responsible car drivers in the group of all car drivers with specified responsibility involved in motorway accidents with respect to age and gender of the driver 
crashes, which account together for over $90 \%$ of motorway crashes in our data: run-off crashes, rear-end crashes, and lane change crashes. Using run-off crashes as reference (they account for $46 \%$ of crashes considered here), we observe an inverted U-shaped effect of the age on the share of both rear-end crashes and lane change crashes. This is indicated by the combination of a positive linear age effect and a smaller negative effect of the squared term (conversely as in Table 4). It should again be noted that the linear age and squared age represent a 2nd order polynomial function with linked parameters, which must be interpreted in relation two each other (i.e. not as independent predictors). All effects are highly significant except for the effect of gender on causing a lane change crash, which is insignificantly lower for women. The general pattern is similar for both rear-end and lane change crashes: They are more often caused by middle-aged drivers and male drivers, which means vice versa that young and elderly drivers as well as women have a higher relative risk of run-off crashes.

This result is not surprising given that "risky driving" is a typical male behaviour. On a motorway it can primarily be expressed by tailgating, possibly combined with quick lane changes, and driving with high speed. Male drivers exceed speed limits on motorways indeed more often than women [43]. All of these misbehaviours increase the risk of causing a rear-end or a lane change crash relative to the risk of causing a run-off crash. An additional factor might be that middle-aged drivers may more often be in a hurry (e.g., when commuting to work) than elderly drivers or young drivers.

\section{Limitations: data quality and interpretation of results}

The validity of the results is somewhat limited by the quality of the data used. The optional labelling of the "mainly responsible person" based on the opinion of the police officer gives the main response variable of our analysis a subjective note. The officer's opinion is presumably influenced by his or her personal experience, preferences, dislikes of particular attributes of drivers etc., such that the same crash might be considered differently by different officers. However, according to af Wåhlberg [38], an explicit, accepted and validated definition of responsibility for crashes does not exist at all within the traffic safety research society and, therefore, the attribution of culpability for traffic collisions seems to be a general problem of traffic safety research. Another concern relates to the nature of our response variable, i.e. the responsibility for a crash according to the police. It is not the outcome of a Bernoulli process and therefore, in a strict sense, no binary random variable. Responsible and non-responsible drivers are linked together in different ways depending on the specific circumstances of the accidents. This may have an impact on the estimation process, but the large sample size should make sure that different effects are balanced out such that there remains at least no systematic bias.

Despite these limitations it was worth to use the novel quality of Austrian accident records for the analysis presented in this paper. We identified several relationships between responsibilities for motorway crashes and socio-demographics, which confirmed existing knowledge and provided some new insights.

Some important influencing factors on the risk of causing a crash were not considered in the analysis, in particular the influence of alcohol, the presence of passengers and, most notably, speed. The effect of alcohol has not been separately considered, because only $4 \%$ of drivers were indicated as driving under influence of alcohol, drugs or medicine. The presence of a passenger did not show any influence with the only exception of male drivers who were borderline-significantly more often "mainly responsible" for a crash with a male passenger than with a female one. The driving speed could not be considered because the dataset comprises no information about it. The risk of being involved or causing a crash per mileage of exposure could also not be calculated, because information about the mileage on Austrian motorways by population segments is not available. The most recent Austria-wide mobility survey ([36], p. 104) indicates that men are more often travelling by car as a driver than women $(53 \%$ vs. $29 \%$ of all trips, respectively), but it includes no information on trip distances.

The McFadden's roh-squares of our models are rather low, which means that only a small portion of the variability of the response variable could be explained by our predictors. One reason for this is that we did not use experimental data but aggregated count data from a real life recording system. The responsibility of causing an accident (as perceived by the police) is certainly not only influenced by our predictors alone, but by many other factors which are not recorded in the system. Nonetheless, we identified some highly significant effects, as indicated by the t-ratios of the parameters and the improvement of the log-likelihood of the final models over the corresponding 'constants only' model. Even the smallest improvement (14.23 with 4 parameters in Table 3) is highly significant.

Given these limitations the findings should be carefully interpreted as "apparent tendencies".

\section{Conclusions}

Despite these limitations, the estimation of the relative risk of causing a motorway crash for different groups of drivers by comparing the shares of drivers who were "mainly responsible" for the crash with those who were 
involved in the crash but "not responsible", yields some plausible tendencies, which support well-known knowledge and provide some new insights. The risk of motorcycle drivers and young as well as elderly car drivers turned out to be disproportionally high, although the differences in the risk of causing a crash (on a motorway) are throughout smaller than those in the risk of involvement in a crash (on all roads). Less expected but quite plausible is the increased risk of causing a crash exhibited by drivers of light trucks as well as foreign car drivers compared to Austrian drivers.

Like many other studies our analysis also suggests that male car drivers are more prone to cause a crash than female drivers. However, an excessive risk of young male drivers could not be identified. The gender gap is rather small. At young up to middle age the share of male "mainly responsible" drivers is 3 to $4 \%$ higher than that of female drivers; the differences decrease with increasing age (beyond about 55 years) and finally disappear entirely beyond the age of about 65 . The distribution of types of crashes by gender and age support this result: male drivers and middle-aged drivers are somewhat more prone to cause rear-end and lane change crashes compared to run-off crashes, which seems to indicate riskier driving of this group. The small gender gap in our data suggests that the frequency of using a motorway and the associated experience of driving on it have more influence on the risk of causing a crash than the driver's gender. These findings are in line with Lourens et al. [23], although their findings related to crash involvement. When it comes to the risk of causing a crash on Austrian motorways (as perceived by the police) the "equity of gender" seems to be closer than in many other areas of life.

From these findings we recommend for motorway safety campaigns to focus on the high risk groups mentioned above, which are young and elderly drivers, motorcyclists, foreign drivers and, last but not least, drivers of light trucks. The traffic safety of light trucks should not only be addressed by campaigning but also by suitable policies, e.g. reduced speed limits and increased enforcement of the loading weight. Furthermore, we recommend to address both male and female drivers equally in traffic safety campaigns. The Austrian motorway operator Asfinag took this recommendation already into account and carried out a campaign promoting "Fair driving" with two equivalent pictures displaying two children accompanied by an adult person, one showing a male driver and the other one a female driver.

A final conclusion relates to the Austrian accident recording system described in Section 1. When the former paper-based system was replaced by the standardised computer-based system in January 2012 the annual number of injury crashes registered in Austria suddenly increased by about $15 \%$. Since then, the number is slightly declining year by year, as it was the case before 2011 [33]. This is a strong indication for a reduction of underreporting of crashes in former times. The new system can thus be considered as a definite improvement of the completeness of accident reporting in Austria, despite some limitations with respect to the reporting of optional items by the police.

\begin{abstract}
Acknowledgements
The authors wish to thank all colleagues involved in the project Rücksicht+ for their valuable contributions. Furthermore, the authors wish to thank the reviewers for their thorough job, which helped us to improve the paper a lot.
\end{abstract}

\section{Authors' contributions}

We confirm that this revised manuscript is written by nobody else than us. Both authors read and approved the final manuscript.

\section{Funding}

The research project Rücksicht+, from which the data in this article were derived, was funded by the Austrian motorway operator Asfinag.

\section{Availability of data and materials}

The datasets generated and analysed during the current study are not publicly available, the data basis had not been prepared for a simple treatment by an external person, but are available from the authors on reasonable request.

\section{Competing interests}

The authors declare that they have no competing interests.

Received: 2 August 2018 Accepted: 17 October 2019

Published online: 09 December 2019

\section{References}

1. Aarts, L., \& van Schagen, I. (2006). Driving speed and the risk of road crashes: A review. Accident Analysis \& Prevention, 38, 215-224.

2. Bergel-Hayat, R., Debbarh, M., Antoniou, C., \& Yannis, G. (2013). Explaining the road accident risk: Weather effects. Accident Analysis \& Prevention, 60, 456-465.

3. Berger, W. J., Riegler, S., Juschten, M., Schützhofer, B., Söllner, M., \& Knessl, G. (2016). Basisstudie zu geplanten Kampagnen für mehr Rücksichtnahme im Autobahnverkehr (Rücksichtt). Endbericht (Basic study on planned campaigns for more courtesy in motorway traffic; final report). Wien (unpublished) (p. 116).

4. Brackstone, M., \& McDonald, M. (2007). Driver headway: How close is too close on a motorway? Ergonomics, 50(8), 1183-1195.

5. Broughton J, Baughan C, Pearce L, Smith L, Buckle G (2003) Work-related road accidents Crowthorne: Transport Research Laboratory; TRL Report 582.

6. Constantinou, E., Panayiotou, G., Konstantinou, N., Loutsiou-Ladd, A., \& Kapardis, A. (2011). Risky and aggressive driving in young adults: Personality matters. Accident Analysis \& Prevention, 43, 1323-1331.

7. Cummings, P., Koepsell, T. D., Moffat, J. M., \& Rivara, F. P. (2001). Drowsiness, counter-measures to drowsiness, and the risk of a motor vehicle crash. Injury Prevention, 7, 194-199.

8. Delhomme P, De Dobbeleer W, Forward S, Simões A (Eds.), Adamos G, Areal A, Chappé J, De Dobbeleer W, Delhomme P, Eyssartier C, Forward S, Loukopoulos P, Nathanail T, Nordbake S, Peters H, Phillips R, Pinto M, Ranucci M-F, Sardi GM, Simöes A, Trigoso J, Vaa T, Veisten K, Walter E (2009) Manual for designing, implementing and evaluating road safety communication campaigns. Brussels: IBSR-BIW.

9. Doherty, S. T., Andrey, J. C., \& McGregor, C. (1998). The situational risks of young drivers: The influence of passengers, time of day and day of week on accident rates. Accident Analysis \& Prevention, 30(1), 45-52.

10. Daigneault, G., Pierre, J., \& Frigon, J. Y. (2002). Executive functions in the evaluation of accident risk of older drivers. Journal of Clinical and Experimental Neuropsychology, 24, 221-238. 
11. Elvik, R. (2013). A re-parameterisation of the power model of the relationship between the speed of traffic and the number of accidents and accident victims. Accident Analysis \& Prevention, 50, 854-860.

12. Elvik, R., Høye, A., Vaa, T., \& Sørensen, M. (2009). The handbook of road safety measures (2nd ed.). Bingley: Emerald.

13. Elvik, R. (2006). Laws of accident causation. Accident Analysis \& Prevention, 38, 742-747.

14. FSV - Österreichische Forschungsgesellschaft Straße-Schiene-Verkehr. (2014). RVS 02.02.21 Verkehrssicherheitsuntersuchung. Wien: Road safety investigation.

15. Fisher, D. L., Laurie, N. E., Glaser, R., Connerney, K., Pollatsek, A., Duffy, S. A., \& Brock, J. (2002). Use of a fixed-base driving simulator to evaluate the effects of experience and PC-based risk awareness training on drivers' decisions. Human Factors, 44, 287-302.

16. Forsyth, E., Maycock, G., \& Sexton, B. (1995). Cohort study of learner and novice drivers: Part 3, accidents, offences and driving experience in the first three years of driving. Crowthorne: Project report 111, Trasport research laboratory.

17. Hellinga, L. A., McCartt, A. T., \& Haire, E. R. (2007). Choice of teenagers' vehicles and views on vehicle safety: Survey of parents of novice teenage drivers. Journal of Safety Research, 38, 707-713.

18. Henningsen, A., \& Toomet, O. (2011). maxLik: A package for maximum likelihood estimation in R. Computational Statistics, 26(3), 443-458.

19. Horswil, M. S., \& Helman, S. (2003). A behavioral comparison between motorcyclists and a matched group of non-motorcycling car drivers: Factors influencing accident risk. Accident Analysis \& Prevention, 35, 589-597.

20. Lee, H. C., Lee, A. H., \& Cameron, D. (2003). Validation of a driving simulator by measuring the visual attention skill of adult drivers. The American Journal of Occupational Therapy, 57(3), 324-328.

21. Lee, H. C., Lee, A. H., Cameron, D., \& Li-Tsang, C. (2003). Using a driving simulator to identify older drivers at inflated risk of motor vehicle crashes. Journal of Safety Research, 34, 453-459.

22. Lin, M.-R., \& Kraus, J. F. (2009). A review of risk factors and patterns of motorcycle injuries. Accident Analysis \& Prevention, 41, 710-722.

23. Lourens, P. F., Vissers, J. A. M. M., \& Jessurun, M. (1999). Annual mileage, driving violations, and accident involvement in relation to drivers' sex, age, and level of education. Accident Analysis \& Prevention, 31, 593-597.

24. Lucidi, F., Giannini, A. M., Sgalla, R., Mallia, L., Devoto, A., \& Reichmann, S. (2010). Young novice driver sub-types: Relationship to driving violations, errors and lapses. Accident Analysis \& Prevention, 42, 1689-1696.

25. van der Linden, D., Frese, M., \& Meijman, T. F. (2003). Mental fatigue and the control of cognitive processes: Effects on perseveration and planning. Acta Psychologica, 113, 45-65.

26. Martin, J.-L. (2002). Relationship between crash rate and hourly traffic flow on interurban motorways. Accident Analysis \& Prevention, 34(2002), 619-629.

27. Massie, D. L., Green, P. E., \& Campbell, K. L. (1997). Crash involvement rates by driver gender and the role of average annual mileage. Accident Analysis \& Prevention, 29(5), 675-685.

28. NTSH - National Highway Traffic Safety Administration. (2011). Traffic safety facts 2009: Motorcycles. Washington, DC: National Highway Traffic Safety Administration.

29. Phillips, R. O., Ulleberg, P., \& Vaa, T. (2011). Meta-analysis of the effect of road safety campaigns on accidents. Accident Analysis \& Prevention, 43 1204-1218.

30. Ryan, A., Legge, M., \& Rosman, D. (1998). Age related changes in drivers' crash risk and crash type. Accident Analysis \& Prevention, 30(3), 379-387.

31. Summala, H., \& Mikkola, T. (1994). Fatal accidents among Car and truck drivers: Effects of fatigue, age, and alcohol consumption. Human Factors, 36(2), 315-326.

32. Starkey, N. J., \& Isler, R. B. (2016). The role of executive function, personality and attitudes to risks in explaining self-reported driving behaviour in adolescent and adult male drivers. Transportation Research Part F, 38, 127-136.

33. Statistik Austria (2018) Straßenverkehrsunfälle 2017. (Road traffic accidents 2017) Wien. (https://www.statistik.at/web_de/services/publikationen/14/ index.html?includePage=detailedView\&sectionName=Verkehr\&publd=751)

34. Statistik Austria (2017a) Kfz-Bestand 2016. (Stock of vehicles 2016) Wien. (http://www.statistik.at/web_de/statistiken/energie_umwelt_innovation_ mobilitaet/verkehr/strasse/kraftfahrzeuge___bestand/index.html).

35. Statistik Austria (2017b) Bevölkerung mit Migrationshintergrund im Überblick (Jahresdurchschnitt 2016). (Overview of population with a migration background (annual average 2016) Wien. (https:/www.statistik.at/web_de/statistiken/ menschen und gesellschaft/bevoelkerung/bevoelkerungsstruktur/ bevoelkerung_nach_migrationshintergrund/index.html).
36. Tomschy R, Herry M, Sammer G, Klementschitz R, Riegler S, Follmer R, Gruschwitz D, Josef F, Gensasz S, Kirnbauer R, Spiegel T (2016) Österreich unterwegs 2013/2014. Ergebnisbericht zur österreichweiten Mobilitätserhebung "Österreich unterwegs 2013/2014" (Austria-wide mobility survey 2013/2014; report of results), Herausgeber: Bundesministerium für Verkehr, Innovation und Technologie, Wien.

37. Vaa $T$ (2003) Impairments, diseases, age and their relative risks of accident involvement: Results from meta analysis. TØI report 690/2003, Oslo.

38. af Wåhlberg, A. (2009). Driver behaviour and accident research methodology: Unresolved problems. Ashgate Publishing, Ltd.

39. Wells, S., Mullin, B., Norton, R., Langley, J., \& Connor, J. (2004). Motorcycle rider conspicuity and crash related injury: Case-control study. BMJ, 2004, 328-857.

40. Wickens, C. D., \& Horrey, W. J. (2009). Models of attention, distraction and highway hazard avoidance. In M. A. Regan, J. D. Lee, \& K. L. Young (Eds.), Driver distraction, theory, effects, and mitigation (pp. 57-69). Boca Raton, London, Ney York: CRC Press.

41. Williams, A. F., Leaf, W. A., Simons-Morton, B. G., \& Hartos, J. L. (2006). Vehicles driven by teenagers in their first year of licensure. Traffic Injury Prevention, 7(1), 23-30.

42. Williamson, A. (2009). The relationship between driver fatigue and driver distraction. In M. A. Regan, J. D. Lee, \& K. L. Young (Eds.), Driver distraction, theory, effects, and mitigation (pp. 383-392). Boca Raton, London, Ney York: CRC Press.

43. Yannis, G., Louca, G., Vardaki, S., \& Kanellaidis, G. (2013). Why do drivers exceed speed limits. European Transport Research Review, 5, 165-177.

44. Zeileis, A. (2006). Object-oriented computation of sandwich estimators. Journal of Statistical Software, 16(9), 1-16.

\section{Publisher's Note}

Springer Nature remains neutral with regard to jurisdictional claims in published maps and institutional affiliations.

\section{Submit your manuscript to a SpringerOpen ${ }^{\circ}$ journal and benefit from:}

- Convenient online submission

Rigorous peer review

- Open access: articles freely available online

High visibility within the field

- Retaining the copyright to your article

Submit your next manuscript at $>$ springeropen.com 